\title{
EVALUATION OF THE GENETIC DIVERSITY OF Huperzia serrate BY RAPD MARKERS
}

\author{
Ho Thi Huong ${ }^{1}$, Ngo Thi Thuy Linh ${ }^{1}$, Le Thi Lan Anh², Le Thi Bich Thuy ${ }^{1,2 *}$ \\ ${ }^{1}$ Institute of Biotechnology, VAST \\ ${ }^{2}$ Graduate University of Science and Technology, VAST
}

\begin{abstract}
ABTRACT
Huperzia serrata, a valuable pharmaceutical plant distributed in Lao Cai (Northwest Vietnam) and Lam Dong (Central Highlands of Vietnam), is known as pharmaceutical material for the treatment of Alzheimer's disease. As the result of over-exploitation and habitat fragmentation, $H$. serrata has become a threatened plant in Vietnam, China and other countries around the world. For the understanding of population dynamics, adaptation, evolution and conservation of plant species in general and $H$. serrata in particular, the evaluation of genetic diversity is very important. In this study, the total of 16 RAPD primers were used for evaluation of the genetic diversity of eight $H$. serrata samples collected from different locations of $\mathrm{Sa} \mathrm{Pa}$ and $\mathrm{Da}$ Lat. Overall, 16 markers generated a total of 70 fragments in eight collected samples of $H$. serrata. Of 70 generated fragments, 44 were found to be polymorphic. The number of fragments of each primer ranged from 1 to 8 with an average of 4,4 fragments per primer. The OPB20 primer revealed the highest polymorphism, while the OPB15, OPB17 and OPC12 primers gave the lowest. Polymorphism information content (PIC) values varied from 0.5266 to 0.8624 with an average of 0.7182 , in which the highest value belonged to OPB 11 primer while the OPC10 primer showed the lowest PIC value. The dendrogram created based on RAPD data sheet divided the investigated strain into two major groups corresponding to their habitat: Group I included three Da Lat samples (DL1, DL2, DL3) and Group II consisted of five samples from Sa Pa (SP1, Sp2, SP3, Sp4, and SP5). In conclusion, the results of our study could be useful for the conservation and development of $H$. serrata.
\end{abstract}

Keywords: Huperzia serrata, genetic diversity, pharmaceutical plant, polymorphism, RAPD marker.

Citation: Ho Thi Huong, Ngo Thi Thuy Linh, Le Thi Lan Anh, Le Thi Bich Thuy, 2018. Evaluation of the genetic diversity of Huperzia serrate by rapd markers. Academia Journal of Biology, 40(4): 85-90. https://doi.org/10.15625/2615-9023/v40n4.10848.

*Corresponding author email: 1tbthuy@ibt.ac.vn

Received 2 November 2017, accepted 15 December 2018

\section{INTRODUCTION}

Huperzia serrata, a typical member of the genus Huperzia belonging to the family Lycopodiaceae, comprises about 500 species in the world (Christenhusz et al., 2011; Kitajima \& Takayama, 2011). Known for medicinal value since 739 (the Tang Dynasty), the whole plant of $H$. serrata, named Qian
Ceng Ta (in Chinese), is one of the oldest Chinese herbs and has been extensively used in the clinic to treat contusion, swelling, strains, schizophrenia, myasthenia gavis and organophosphate poisoning (Ma et al., 2007). $H$. serrata produces various types of bioactive lycopodium alkaloids, including huperzine $\mathrm{A}$, a potent drug for $\mathrm{AD}$. Huperzine A was first isolated from the whole plant of $H$. serrata by 
Chinese scientists Liu and his co-worker (Liu et al., 1986a, b). Huperzine A, under the trade name "Cerebra", is currently used in the United States as a supplementary drug for patients with memory impairment. Nowadays it is marketed as a "smart drug" to boost brain power.

$H$. serrata is mainly found in sub-tropical to temperate forests at an altitude of 900 to $3500 \mathrm{~m}$ in many countries, such as Australia, China, Cuba, Fiji, India, Indonesia, Japan, Korea, Mexico, Myanmar, Nepal, Peninsular Malaysia, Russia, Samoa, Sri Lanka, Thailand, Taiwan, USA and Vietnam (Singh \& Singh, 2010, Dixit, 1984). In Vietnam, H. serrata is distributed in $\mathrm{Sa} \mathrm{Pa}$ (Lao Cai) and Da Lat (Lam Dong), where the elevation is above $1000 \mathrm{~m}$, and it frequently grows in shaded, damp habitats with moist, acidic humus soil. The whole plant of $H$. serrata has been found to be the major source of huperzine $\mathrm{A}$, a potent, reversible and selective acetylcholine esterase inhibitor (AChEI). Synthesis of huperzine A has not been industrialized yet, and it is primarily extracted from natural resources (Ma et al., 2005). The rapidly growing demand and the high price of the raw materials are increasing pressure on the natural habitats. Furthermore, these plants grow extremely slowly (Ma et al., 2007; Ma \& Gang, 2004). As the result of overexploitation and habitat fragmentation, $H$. serrata has become a threatened plant in Vietnam, China and other countries around the world (Tran Hop, 2005; Ma et al., 2007).

Studying the genetic diversity of rare plants not only enhances our understanding of population dynamics, adaptation and evolution, but also provides useful information for biological conservation (Schaal et al., 1991).

Molecular markers are powerful tools for analyzing genetic diversity (Ouborg et al., 1999). DNA fingerprinting can distinguish species rapidly using a small amount of DNA, thus providing useful information for phylogenetic analysis. Various approaches are available for DNA fingerprinting, such as AFLP (Amplified Fragment Length Polymorphism), SSR (Simple Sequence Repeats) and RAPD (Random Amplified Polymorphic DNA). RAPD is convenient and simple, hence the most common method to check genetic similarity and phylogenetic relationship (Gepts, 1993). Once DNA fragments are amplified by polymerase chain reaction (PCR) using primers with arbitrary sequences, a rapid screening for polymorphism can be performed, enabling diversity analysis of several plants simultaneously (Williams et al., 1990). In this study, we will evaluate the genetic diversity of eight $H$. serrata samples representing for eight populations in $\mathrm{Sa} \mathrm{Pa}$ and $\mathrm{Da}$ Lat based on RAPD markers.

\section{MATERIALS AND METHODS}

\section{Sampling sites and plant materials}

The plant materials used in this study were collected from eight populations across the main niches of $H$. serrata in $\mathrm{Sa} \mathrm{Pa}$ (Lao Cai) and Da Lat (Lam Dong), Vietnam. Locations of the eight natural populations were listed in table 1 .

Table 1. Locations of the eight natural populations

\begin{tabular}{|c|c|c|}
\hline No & Location & $\begin{array}{c}\text { Population } \\
\text { code (Sample) }\end{array}$ \\
\hline 1 & Bidoup-Nui Ba & DL1 \\
\hline 2 & Don Duong-Lam Dong & DL2 \\
\hline 3 & Nam Ban-Lam Ha & DL3 \\
\hline 4 & Nam Cang-Sa Pa & SP1 \\
\hline 5 & Ban Ho-Sa Pa & SP2 \\
\hline 6 & Ta Van-Sa Pa & SP3 \\
\hline 7 & Lao Chai-Sa Pa & SP4 \\
\hline 8 & Ta Phin-Sa Pa & SP5 \\
\hline
\end{tabular}

\section{RAPD primers}

16 RAPD primers used in RAPD-PCR reactions were purchased from Operon, USA (Table 2). 
Table 2. List of RAPD primers used

\begin{tabular}{|c|c|c|c|c|c|}
\hline No & $\begin{array}{c}\text { RAPD } \\
\text { primer }\end{array}$ & Nucleotide sequence (5'-3') & No & $\begin{array}{c}\text { RAPD } \\
\text { primer }\end{array}$ & Nucleotide sequence (5'-3') \\
\hline 1 & OPB1 & GTTTCGCTCC & 9 & OPC1 & TTCGAGCCAG \\
\hline 2 & OPB4 & GGACTGGAGT & 10 & OPC5 & GATGACCGCC \\
\hline 3 & OPB8 & GTCCACACGG & 11 & OPC6 & GAACGGACTC \\
\hline 4 & OPB11 & GTAGACCCGT & 12 & OPC10 & TGTCTGGGTG \\
\hline 5 & OPB13 & TTCCCCCGCT & 13 & OPC12 & TGTCATCCCC \\
\hline 6 & OPB15 & GGAGGGTGTT & 14 & OPC13 & AAGCCTCGTC \\
\hline 7 & OPB18 & CCACAGCAGT & 15 & OPC17 & TTCCCCCAG \\
\hline 8 & OPB20 & GGACCCTTAC & 16 & OPC19 & GTTGCCAGCC \\
\hline
\end{tabular}

\section{Extraction of genomic DNA}

DNA was extracted from young leaves of H. serrata using CTAB method. $20 \mathrm{mg}$ of plant tissues were ground, mixed with $600 \mu \mathrm{L}$ of freshly-prepared and preheated $2 \mathrm{X} \mathrm{CTAB}$ solution in a $1.5 \mathrm{~mL}$ tube, and incubated at $65^{\circ} \mathrm{C}$ for 60 mins. The supernatant was added to $600 \mu \mathrm{L}$ of chloroform/isoamyl alcohol (24:1), vortexed for a few seconds and centrifuged at 12,000 g for 15 mins. DNA was then precipitated overnight with an equal volume of ice-cold isopropanol. Next day, DNA was pelleted by 15 mins centrifugation at $12,000 \mathrm{~g}$ and decanting before letting air dry. DNA pellet was washed by adding $600 \mu \mathrm{L}$ of cooled $\left(4^{\circ} \mathrm{C}\right) 70 \%$ ethanol and centrifuging for $15 \mathrm{mins}$ at $12,000 \mathrm{~g}$. After decanting ethanol, $100 \mu \mathrm{L}$ of TE buffer (10 $\mathrm{mM}$ Tris-HCl, $1 \mathrm{M}$ MEDTA, $\mathrm{pH}$ 8.0) was added and the mixture was incubated at $65^{\circ} \mathrm{C}$ for $60 \mathrm{~min} .4 \mu \mathrm{L}$ of RNAase $(10 \mathrm{mg} / \mathrm{mL})$ was, followed by a 60 mins incubation at $37^{\circ} \mathrm{C}$. The purity DNA was measured by the ratio of the absorbance at 260 and $280 \mathrm{~nm}$. DNA of five plants from a population was pooled to form the sample representing for appropriate population.

\section{PCR amplification}

PCR reaction was performed as described by Williams et al. (1990). The final volume of $25 \mu \mathrm{L}$ contained $10 \mathrm{X}$ buffer $(50 \mathrm{mM} \mathrm{KCl}$, $10 \mathrm{mM}$ Tris- $\mathrm{HCl} \mathrm{pH} 8.3,1.5 \mathrm{mM} \mathrm{MgCl} 2$, and $0.001 \%(\mathrm{w} / \mathrm{v})$ gelatin), $50 \mathrm{ng}$ of template DNA, $0.25 \mathrm{mM}$ dNTPs (Thermo Scientific),
$0.025 \mathrm{mM}$ of primers, $1.5 \mathrm{mM} \mathrm{MgCl} 2$ and $1 \mathrm{U}$ of Taq polymerase. Reaction mixtures were amplified in PTC-100 (MJ Research Inc., USA), each reaction was performed using an initial step of $94^{\circ} \mathrm{C}$, followed by 35 cycles of 1-min denaturation at $94^{\circ} \mathrm{C}, 1-\mathrm{min}$ annealing at $37^{\circ} \mathrm{C}$ and 2 -mins extension at $72^{\circ} \mathrm{C}$, and terminated by 5 -mins extension at $72^{\circ} \mathrm{C}$. At PCR completion, samples were kept at $4^{\circ} \mathrm{C}$ for analysis. RAPD products after PCR were separated by electrophoresis on $1 \%$ agarose gel in $1 \mathrm{X}$ TBE (Tris boric acid EDTA) buffer using ethidium bromide staining and visualized under UV light.

\section{Data analysis}

Target DNA amplicons were scored (present $=1$, absent $=0$ ) for each appropriate marker (bp). Faint bands were considered. Results were then entered in NTedit1.2a software accordingly. A phylogenetic tree was constructed using NTSYSpc 2.1 (Numerical Taxonomy and Multivariate Analysis System version 2.1) software (Rohlf, 2000).

\section{RESULTS AND DISCUSSION}

PCR-RAPD products were analyzed by 16 RAPD primers on $1 \%$ agarose gel electrophoresis for DNA polymorphism analysis of eight samples of $H$. serrata (Table $3)$. Of 16 primers, 15 were polymorphic, only one (OPB13) showed no polymorphism. The number of amplified fragments by each primer varied from 1 (OPB13 primer) to 8 (OPB4 and OPB11 primer) with an average of 
4.4. A total of 70 amplified fragments were obtained. Among these 70 fragments, 44 were found to be polymorphic. The average PIC coefficient of the primers was quite high
(0.7182). In particular, OPB11 primer (Fig. 1) had the highest PIC value (0.8624) and OPC10 primer (Fig. 2) had the lowest PIC value (0.5266).

Table 3. Primer sequences, total number of polymorphic bands, percentage of polymorphism and PIC value of the primers used

\begin{tabular}{|c|c|c|c|c|c|}
\hline No. & $\begin{array}{c}\text { Name of } \\
\text { Primers }\end{array}$ & Total fragments & $\begin{array}{c}\text { Polymorphic } \\
\text { fragments }\end{array}$ & $\begin{array}{c}\text { Percentage of polymorphic } \\
\text { fragments }\end{array}$ & PIC values \\
\hline 1 & OPB1 & 6 & 5 & 83,3 & 0.8164 \\
\hline 2 & OPB4 & 8 & 7 & 87,5 & 0.8356 \\
\hline 3 & OPB8 & 4 & 2 & 50 & 0.7407 \\
\hline 4 & OPB11 & 8 & 4 & 50 & 0.8624 \\
\hline 5 & OPB13 & 1 & 0 & 0 & 0 \\
\hline 6 & OPB15 & 6 & 2 & 33,3 & 0.8286 \\
\hline 7 & OPB17 & 3 & 1 & 33,3 & 0.5926 \\
\hline 8 & OPB20 & 2 & 2 & 100 & 0.6600 \\
\hline 9 & OPC1 & 5 & 4 & 80 & 0.7300 \\
\hline 10 & OPC5 & 7 & 4 & 57,1 & 0.8245 \\
\hline 11 & OPC6 & 4 & 3 & 75 & 0.7107 \\
\hline 12 & OPC10 & 2 & 1 & 50 & 0.5266 \\
\hline 13 & OPC12 & 3 & 1 & 33,3 & 0.6205 \\
\hline 14 & OPC13 & 3 & 2 & 66,7 & 0.6044 \\
\hline 15 & OPC17 & 4 & 3 & 75 & 0.7050 \\
\hline 16 & OPC19 & 4 & 3 & 75 & 0.7150 \\
\hline & Total & $\mathbf{7 0}$ & $\mathbf{4 4}$ & & $\mathbf{0 . 7 1 8 2}$ \\
\hline & Average & $\mathbf{4 . 4}$ & $\mathbf{2 . 8}$ & & \\
\hline
\end{tabular}

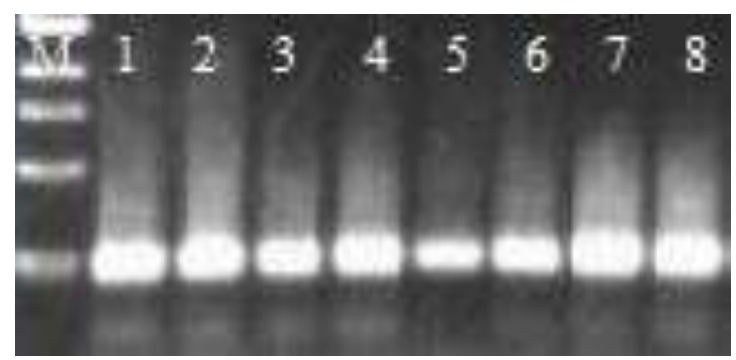

Figure 1. RAPD patterns of eight $H$. serrata samples generated by primer OPB10 (M: marker Thermo Scientific 1kb, 1-8: 8 sample of $H$. serrata)

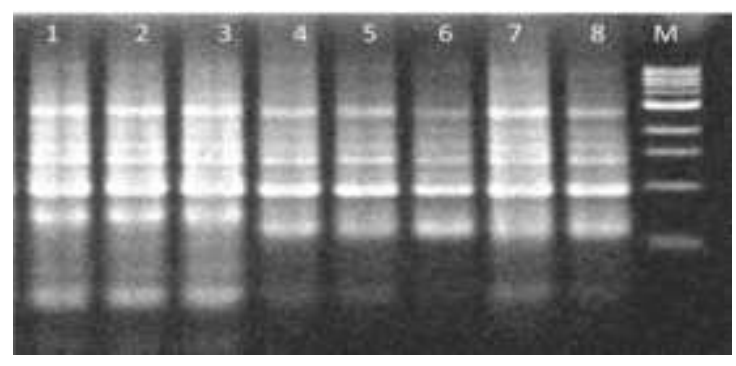

Figure 2. RAPD patterns of eight $H$. serrata samples generated by primer OPB11 (M: marker Thermo Scientific $1 \mathrm{~kb}, 1-8: 8$ sample of $H$. serrata) 
Results of genetic relationship analysis between the eight samples

Based on the data obtained by analyzing eight samples of $H$. serrata with 16 RAPD primers and using NTSYSpc version 2.1 software to calculate the genetic similarity coefficients between samples, the results are shown in table 4.
The genetic similarity coefficient of eight $H$. serrata samples ranged from 0.5217 to 0.9420. Among eight samples belong to eight locations, DL2 and DL3, SP1 and SP2 had the highest similarity coefficient (0.9420). DL1 and SP2 had the most distant genetic relationship, revealed by the lowest coefficient (0.5217).

Table 4. Similarity coefficient of eight different $H$. serrata samples

\begin{tabular}{|l|c|c|c|c|c|c|c|c|}
\hline & DL1 & DL2 & DL3 & SP1 & SP2 & SP3 & SP4 & SP5 \\
\hline DL1 & 1.0000000 & & & & & & & \\
\hline DL2 & 0.8405797 & 1.0000000 & & & & & & \\
\hline DL3 & 0.8115942 & 0.9420290 & 1.0000000 & & & & & \\
\hline SP1 & 0.5507246 & 0.5652174 & 0.5942029 & 1.0000000 & & & & \\
\hline SP2 & 0.5217391 & 0.5362319 & 0.5362319 & 0.9420290 & 1.0000000 & & & \\
\hline SP3 & 0.5942029 & 0.5797101 & 0.5797101 & 0.8695652 & 0.8405797 & 1.0000000 & & \\
\hline SP4 & 0.5652174 & 0.5507246 & 0.5797101 & 0.8695652 & 0.8695652 & 0.9130435 & 1.0000000 & \\
\hline SP5 & 0.66666667 & 0.6521739 & 0.6521739 & 0.8260870 & 0.7971014 & 0.8115942 & 0.8115942 & 1.0000000 \\
\hline
\end{tabular}

In the diagram of genetic relationship in figure 3 , eight samples of $H$. serrata were divided into two major groups ( I and II). Group I consisted of $H$. serrata samples collected from Da Lat (DL1, DL2, DL3), which were further sub-divided by their genetic similarity. DL2 and DL3 showed the highest genetic correlation (0.9420), indicating they were closer to each other than to DL1. Group II comprised of five samples of $H$. serrata from $\mathrm{Sa} \mathrm{Pa}$. This group could also be split up in to sub-group II.1 and II.2. The former was made up of SP1, SP2, SP3, SP4, in which SP1 and SP2 were most closely related with a similarity coefficient of 0.9420 . SP5 sample had the most distant genetic relationship from the rest of $\mathrm{Sa} \mathrm{Pa}$ samples, hence constituting a distinct branch.

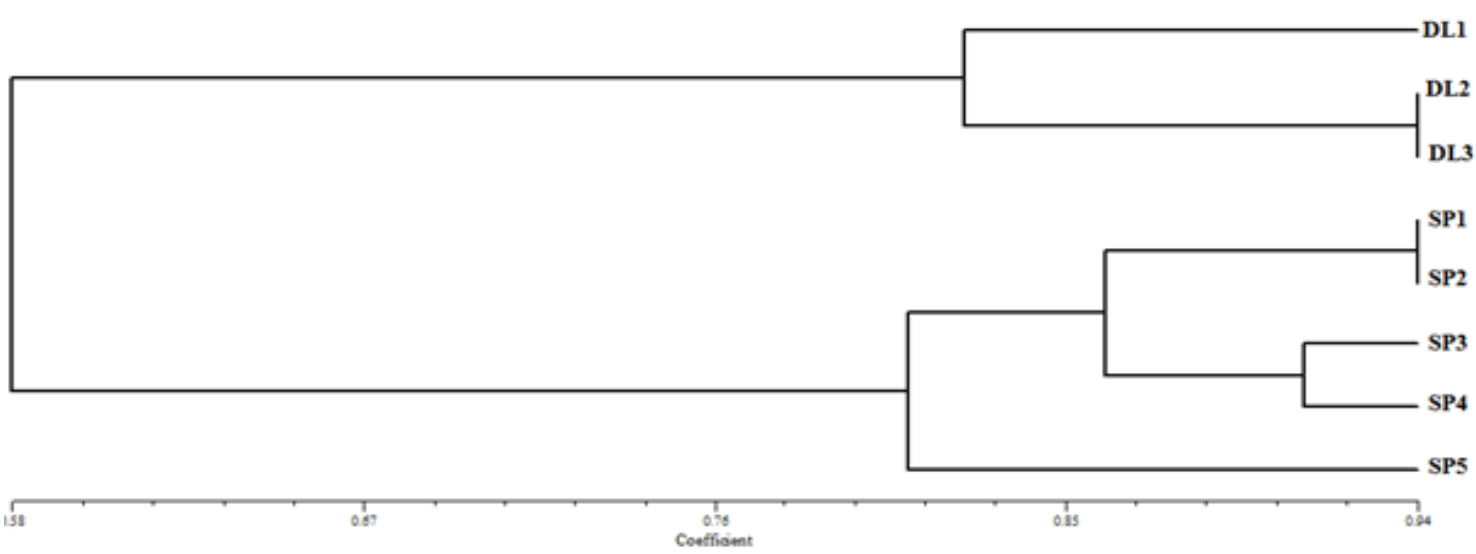

Figure 3. UPGMA dendrogram of cluster analysis of RAPD markers illustrating the genetic relationships among eight investigated samples of $H$. serrata 
DNA fingerprinting analysis of eight $H$. serrata samples collected from $\mathrm{Sa} \mathrm{Pa}$ and Da Lat showed that the genetic correlations among them were quite high. In terms of geography, we concluded that samples from neighboring areas, such as Nam Cang-Sa Pa, Ban Ho-Sa Pa or Ta Van-Sa Pa, Lao Chai-Sa $\mathrm{Pa}$ were closely related and it was possible that they evolved from a common ancestor.

\section{CONCLUSION}

Out of 16 analyzed RAPD primers, 15 were polymorphic and generated 70 DNA fragments, 44 of which were polymorphic. The number of amplified DNA fragments ranged from 1 to 8 . The average PIC value of primers was 0.7182 . In particular, OPB11 primer had the highest PIC value (0.8624) and OPC10 primer had the lowest PIC value (0.5266). Based on their genetic similarity, eight $H$. serrata samples were divided into two main groups corresponding to their habitat: Group I included three Da Lat samples (DL1, DL2, DL3) and Group II consisted of five samples from Sa Pa (SP1, Sp2, SP3, Sp4 and SP5). The results of our study could be useful for the conservation and development of $H$. serrata.

\section{REFERENCES}

Christenhusz M., Zhang X., Schneider H., 2011. A linear sequence of extant families and genera of lycophytes and ferns. Phytotaxa, 19(1): 7-54.

Gepts P., 1993. The use of molecular and biochemical markers in crop evolution studies. Evol Biol, (27): 51-94.

Dixit R.D., 1984. A census of the Indian Pteridophytes. Botanical survey of India, Howrah.

Kitajima M., Takayama H., 2011. Lycopodium alkaloids: isolation and asymmetric synthesis. Springer, 1-31.
Liu J. S., Yu C. M., Zhou Y. Z., Han Y. Y., Wu F. W., Qi B. F., Zhu Y. L., 1986a. Study on the chemistry of huperzine-A and huperzine-B. Acta Chimica Sinica, (44): 1035-1040.

Liu J. S., Zhu Y. L., Yu C. M., Zhou Y. Z., Han Y. Y., Wu F. W., Qi B. F., 1986 b. The structures of huperzine $\mathrm{A}$ and $\mathrm{B}$, two new alkaloids exhibiting marked anticholinesterase activity. Canadian Journal of Chemistry, (64): 837-839.

Ma X., Tan C., Zhu D., Gang D. R., Xiao P., 2007. Huperzine a from huperzia speciesan ethnopharmacolgical review. $J$ Ethnopharmacol, 113(1): 15-34.

Ma X. Q., Gang D. R., 2004. The lycopodium alkaloids. Nat. Prod. Rep., 21: 752-772.

Ouborg N.J., Piquot Y., Groenendael J. M., 1999. Population genetics molecular markers and the study of dispersal in plants. J. Ecol, (87): 551-568.

Rohlf F. J., 2000. Programa NTSYS-pc: numerical taxonomy and multivariate analysis system: version 2.1. Exeter Software. New York, 83p.

Schaal B. A., Leverich W. J., Rogstad S. H., 1991. Comparison of methods for assessing genetic variation in plant conservation biology. In: Falk, D.A., Holsinger, K.E. (Eds.), Genetics and Conservation of Rare Plants. Oxford University Press. New York, pp. 123-134.

Singh H., Singh M., 2010. Huperzia serrata: a promising medicinal pteridophyte from northeast India. NeBIO, 1(1): 27-34.

Tran Hop, 2000. Vietnamese medicinal plants. Agriculture publishing house, pp 110.

Williams J. G., Kubelik A. R., Livak K. J., Rafalski J. A., Tingey S. V., 1990. DNA polymorphisms amplified by arbitrary primers are useful as genetic markers. Nucleic Acids Res., 18(22): 6531-6535. 